\title{
Coronary artery occlusion following blunt chest trauma: a case report and review of the literature
}

\author{
Gregory T. Guldner, MD, MS; ${ }^{*}$ Thomas D. Schilling, $\mathrm{MPH}^{\dagger}$
}

\begin{abstract}
Blunt chest trauma causing coronary artery occlusion and myocardial infarction is a rare but potentially fatal condition. We present the case of a healthy 29 -year-old man who developed a myocardial infarction due to complete occlusion of the proximal right coronary artery following blunt chest trauma. A review of the literature found 63 cases of previously healthy patients under 40 years of age who developed coronary artery occlusion following blunt chest trauma; diagnosis in all cases had been proven by angiography or during autopsy. The presentation, results of electrocardiography and echocardiography and laboratory findings of these patients are described.
\end{abstract}

Key words: myocardial infarction; coronary artery; chest pain; trauma

RÉSUMÉ

Le traumatisme abdominal fermé entraînant une occlusion de l'artère coronaire et un infarctus du myocarde est une atteinte rare mais pouvant être fatale. Nous présentons le cas d'un jeune homme âgé de 29 ans auparavant en bonne santé qui fut victime d'un infarctus du myocarde dû à une occlusion complète de la portion proximale de l'artère coronaire droite à la suite d'un traumatisme abdominal fermé. Une revue de la littérature a permis de trouver 63 cas d'occlusion de l'artère coronaire découlant d'un traumatisme abdominal fermé. Ces patients étaient tous âgés de moins de 40 ans et étaient auparavant en bonne santé. Dans tous les cas, le diagnostic avait été prouvé lors d'une angiographie ou d'une autopsie. Nous décrivons la présentation, les résultats de l'électrocardiographie et de l'échocardiographie et les résultats de laboratoire pour ces patients.

\section{Introduction}

Most patients presenting with blunt chest trauma complain of chest pain or dyspnea. Although the vast majority of these patients will have only minor injuries that account for their pain, some will have serious underlying conditions that require specific therapy. Pneumothorax, cardiac tamponade, and acute aortic tear are considered in the dif- ferential diagnosis for these trauma patients. Myocardial infarction (MI) as a cause of chest pain is not generally considered in patients with blunt chest trauma unless MI is thought to have preceded the traumatic incident. In patients with chest pain clearly related to an impact to the chest, and in those without classic risk factors for coronary artery disease, trauma-induced MI is rarely considered in the differential diagnosis.

*Department of Emergency Medicine, Loma Linda University Medical Center, Loma Linda, Calif.

tLoma Linda University School of Medicine, Loma Linda, Calif.

Received: July 6, 2004; final submission: Nov. 24, 2004; accepted: Dec. 6, 2004

This article has been peer reviewed.

Can J Emerg Med 2005;7(2):118-23 
We present the case of a young healthy man with blunt chest trauma causing the complete occlusion of the right coronary artery (RCA) resulting in an inferior MI. We then review the literature related to young previously healthy adults with proven coronary artery occlusion following blunt chest trauma.

\section{Case report}

A 29-year-old previously healthy man who was riding a motorcycle was struck on his left side by a car travelling at about $50 \mathrm{~km} / \mathrm{h}$. The car rolled over his left leg, left shoulder, chest and abdomen. He had normal vital signs in the field and a normal neurological examination. He complained of upper back pain, leg pain and dyspnea. He was transported to a local emergency department, where radiographs demonstrated a left midshaft femur fracture and a right scapular fracture. Results of chest radiography and contrast-enhanced CT of the chest were normal. Laboratory studies at that time showed a creatine kinase (CK) of 7137, 4.5\% of which was CK-MB. A qualitative troponin test was positive. A rhythm strip to evaluate for arrhythmias related to a possible cardiac contusion showed a normal sinus rhythm. A 12-lead
ECG was not obtained at the initial ED.

He was transferred to a regional trauma centre, where a 12-lead ECG was ordered. Results of the 12-lead ECG showed ST-segment elevation of 4-mm in leads II, III, and aVF, pathologic Q waves in III and aVF, an incomplete right bundle branch block and a sinus rhythm (Fig. 1). A transthoracic and transesophageal echocardiogram, ordered to rule out cardiac tamponade, showed a markedly dilated right ventricle, akinesis of the inferior wall, an ejection fraction of $65 \%$, and no pericardial effusion. A cardiology consultation was obtained, and the patient underwent angiography, which demonstrated $100 \%$ occlusion of the proximal RCA with associated thrombus. There was mild collateral filling from the distal left anterior descending (LAD) artery, and the remainder of the coronary vasculature was normal.

The patient was treated medically with ASA therapy, nitroglycerin, beta-blockade and angiotensin converting enzyme (ACE) inhibitors. Systemic thrombolytics were withheld due to the recent trauma. Angioplasty was not an option because of the complete luminal occlusion, and coronary artery bypass was considered too invasive for this lesion. His femur fracture was repaired and he was discharged from the hospital after 14 days.

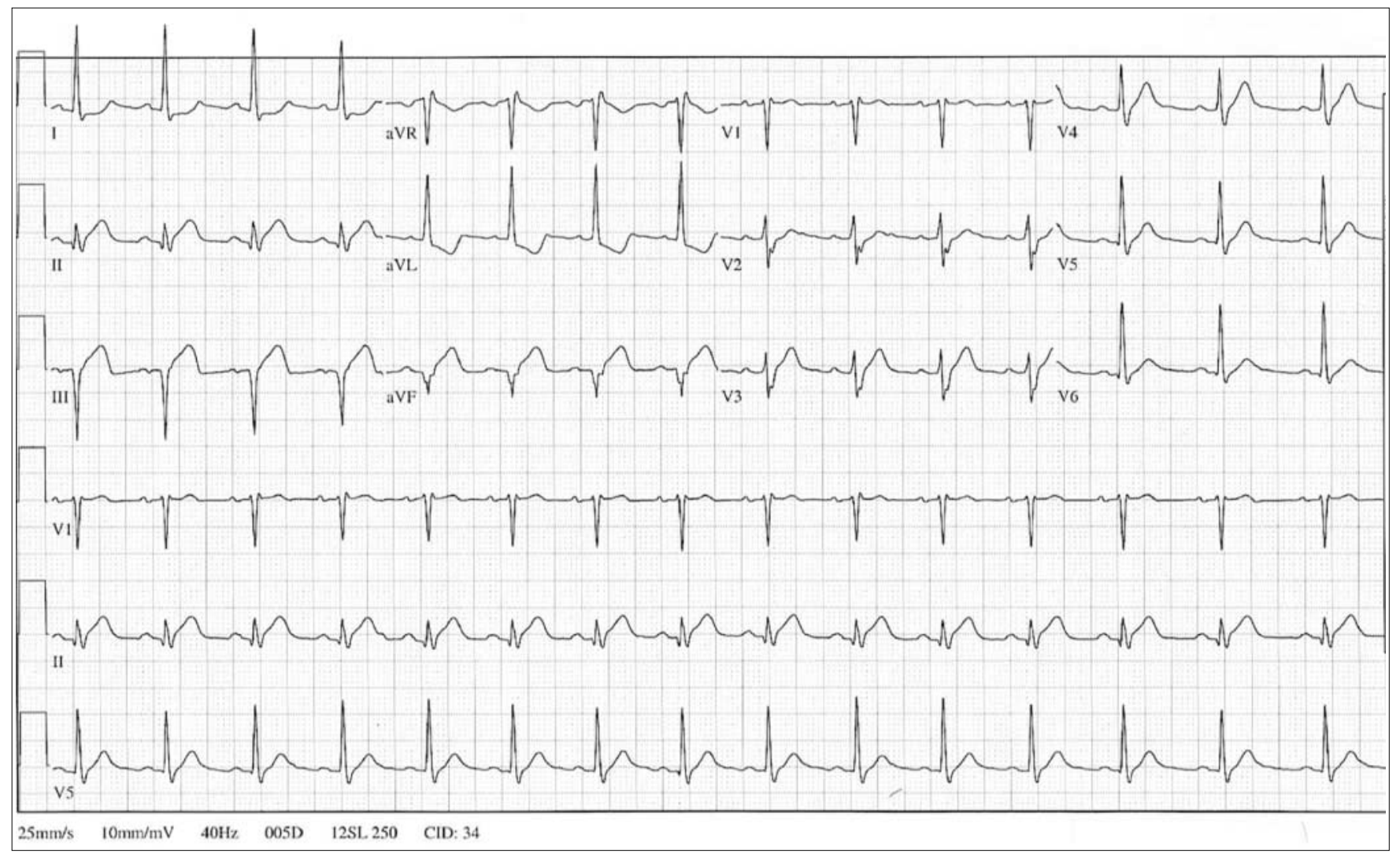

Fig. 1. Results of a 12-lead ECG taken after the patient was transferred to a regional trauma centre. 


\section{Materials and methods}

We conducted a review of the literature looking for case reports of blunt chest trauma resulting in angiographically or autopsy-proven coronary artery occlusion in patients without pre-existing risk factors for MI. The methods utilized in article retrieval, as well as the scope of the study, were approved by an internal investigational review board. We began with a MEDLINE review using key words "blunt chest trauma" and "myocardial infarction." Articles were included if they were in English and provided clinical information on one or more patients with blunt trauma and an MI documented by angiogram or autopsy. Cases were excluded if the patient was under 15 years old, had a prior history of coronary artery disease, if there was an asymptomatic period between the injury and the diagnosis of MI, or if the patient had documented hypercholesterolemia, hypertension, diabetes mellitus, collagen vascular disease, hypercoagulability or known family history of premature heart disease. Patients under 15 (our institutional age cutoff for adult v. pediatric trauma) were excluded to avoid combining adult and pediatric patients. Pediatric patients display different injury patterns following thoracic trauma, due to greater compliance of their chest wall. Patients older than 40 were also excluded, both to eliminate the risk of inadvertently including patients with pre-existing heart disease and to limit the review to our population of interest specifically, younger adult patients in whom heart disease is usually not suspected. We reviewed the references of all articles retrieved from the computerized search for additional cases.

\section{Results}

The search strategy returned 58 articles containing 62 cases that met our criteria. ${ }^{1-58}$ Including the case report above, a total of 63 cases were identified.

\section{Demographics and mechanisms of trauma}

Of the 63 patients, 57 were male. The mean and median age was 28.1 and 29 years, respectively, with a range of 16 to 40 years. Ethnicity was reported in only 11 patients, all of whom were Caucasian. Thirty patients presented for evaluation the same day as the trauma, 4 presented after 1 day, 7 within 5 days, 2 in 2 weeks, 1 at 21 days, and 19 cases did not provide this information.

The initial traumatic event included automobile collisions (24), motorcycle accidents (13), pedestrian hit by a motorcycle (1), bicyclist hit by motorcycle (1), bicycle accident (2), fall from height (1), crush injury (no further de- tails) (1), water-skiing accident (1), fight/struck with fist or elbow (2), contact with other player during sports (9), struck in chest by a ball (3), skiing accident (1), plane crash (1), crushed in closing car door (1), and struck in the chest by an umbrella tip (1). One case did not provide enough information to determine the initial trauma.

\section{Presenting complaints and physical examination of the chest}

Of the 45 patients with presenting complaints described, 38 presented with chest pain, 20 who described their pain as "severe." Four patients had pleuritic or reproducible chest pain and 5 patients had no chest pain, although 3 of these had dyspnea. Two patients were unconscious and unable to give a history.

Thirty patients had a physical exam of the chest wall described. Twenty of these had an abnormal chest exam with tenderness, ecchymosis, hematoma, abrasion, subcutaneous emphysema or contusion. Ten were specifically noted to have a normal chest examination.

Of the 38 patients with blood pressure noted, only 5 were hypotensive (systolic blood pressure $<90 \mathrm{~mm} \mathrm{Hg}$ ). Similarly, only 11 patients out of 34 with documented pulse rates had a rate greater than 100 beats/min.

\section{Laboratory tests, radiography and ECG findings}

Thirty-five patients had an initial CK drawn on evaluation and described in the case report. Thirty-two of these were elevated, with a range of 257 to $>10000 \mathrm{U} / \mathrm{L}$. Three patients had an initial CK in the normal range. Twenty-three patients had both a CK and CK-MB measured, and 18 of these had an elevated MB fraction ( $>4 \%$ of total CK). Three patients had a quantitative test for troponin, 2 of which were normal and 1 was elevated $(5.7 \mathrm{ng} / \mathrm{mL})$. One patient (the case reported above) had a qualitative test for troponin performed, which was positive.

Forty-five patients had the results of chest radiography described in the case reports. Eighteen were normal, and 27 showed the following abnormalities (some patients had multiple findings): rib fractures (11), pulmonary contusions (7), pulmonary edema (4), cardiomegaly (6), abnormal mediastinum (4), pleural effusions (3), pneumothorax (5), sternal fracture (1) and scapular fracture (1).

Forty-five patients had the results of ECG on presentation described in the case report. Only 1 was described as "normal," and this patient had a CK of 900 with $22 \% \mathrm{MB}$ fraction. The remaining 44 ECGs were consistent with acute MI (AMI) patterns; specifically, ST-segment elevation or pathologic Q waves suggesting anterior MI (23), anterolateral MI (11), inferior MI (5), lateral MI (1), infe- 
rior and lateral MI (1) and anterior and inferior MI (2). One case did not provide the specific location of the MI pattern. In addition to the ischemic changes, 6 ECGs showed a right bundle branch block pattern (3 associated with anterior MI and 3 with inferior MI patterns), 1 ECG showed atrioventricular dissociation with an inferior MI, 1 showed a 2:1 arterial-venous (A:V) block with inferior MI, and 1 captured an episode of non-sustained ventricular tachycardia.

Seventeen patients underwent echocardiography on presentation. Sixteen showed wall motion abnormalities consistent with ischemia. One showed no wall motion abnormalities but showed a hypertrophic left ventricle and asymmetric septal hypertrophy. Three studies showed reduced ejection fraction (these also showed wall motion abnormalities). One transesophageal echocardiogram demonstrated a proximal LAD intimal flap later confirmed by angiography.

\section{Angiography and autopsy reports}

Abnormal coronary arteries were shown on angiography for 60 patients. Fifty-eight had a single-vessel obstruction, most often the LAD $(n=45)$. The RCA demonstrated occlusion in 10 cases, the circumflex artery in 2 cases and the left main coronary artery in 1 . Two patients had obstructions noted in more than one coronary artery. One had a subtotal proximal occlusion of the RCA as well as a total occlusion of the proximal LAD. One patient had a total occlusion of the proximal LAD and a subtotal occlusion of the circumflex artery.

Three patients did not have angiography but had coronary artery occlusion confirmed on autopsy. The first showed bruising of the right atrium and interventricular septum, a mural thrombus of the RCA $0.5 \mathrm{~cm}$ from its origin, and a breach in the internal elastic lamina. ${ }^{4}$ The second patient had a 2-cm long hematoma adjacent to the LAD artery, beginning a few millimetres from its origin, which compressed the coronary artery almost completely. No thrombus was found in the artery itself. ${ }^{23}$ The third patient had a thrombus of the LAD beginning approximately 0.5 $\mathrm{cm}$ from its origin. ${ }^{27}$

\section{Discussion}

Post-traumatic coronary artery occlusion is a rare complication of blunt chest trauma and, as with any rare event, information about this process is correspondingly difficult to obtain. Although there are multiple case reports documenting MI in the setting of blunt trauma, many of these cases involve patients with cardiac risk factors such as advanced age or pre-existing heart disease. Thus, some of these reports may represent MI that either preceded the trauma or resulted from the general physiologic stresses of trauma rather than the trauma itself. We sought to describe the subset of patients without known pre-existing risk factors and with proven coronary artery occlusion.

Although most of the 63 cases described resulted from relatively significant mechanisms such as an automobile collision, nearly 1 in 3 resulted from minor incidents such as a football tackle or an elbow to the chest during a basketball game. Most patients presented with symptoms of chest pain that were considered classic for MI (substernal pressure radiating to the shoulder or jaw) or with pain that was considered severe. However, a substantial minority presented with chest pain that was pleuritic or atypical for ischemia. Similarly, a majority of patients had evidence of chest wall trauma (contusions, abrasions, hematomas), but 1 in 4 had a normal chest exam. This suggests that not only is post-traumatic MI a rare condition but, when present, can easily be overlooked if relying solely on the history and physical examination to exclude this condition.

The clinical approach to a blunt chest trauma patient complaining of continued chest pain or dyspnea is not well defined in terms of detecting coronary artery occlusion. The condition has a very low incidence, so the pre-test likelihood for any given patient should correspondingly be very low. Certain conditions such as unexplained hypotension or pulmonary edema should raise one's suspicion. Even with this caveat, the extent of evaluation required to rule out coronary artery occlusion on any given patient is unclear.

The ECG seemed to be the most useful non-invasive test, showing an AMI pattern in almost all patients in this series. While ECG abnormalities are present in up to $63 \%$ of blunt chest trauma patients, only $2 \%$ of patients demonstrate MI patterns. ${ }^{59}$ Patients without an MI pattern could likely forgo further evaluation, given the already low likelihood of this condition. Those with MI patterns may be candidates for an echocardiogram. All of the cases that had echocardiograms performed had abnormal findings suggesting MI.

Unfortunately, cardiac contusion can mimic AMI due to coronary artery occlusion on echocardiography, ${ }^{60}$ leading to an unnecessary coronary angiogram. Cardiac markers may also be helpful, although they cannot differentiate myocardial damage due to cardiac contusion versus coronary artery obstruction. Patients with elevated or rising troponin levels, an ECG with an AMI pattern, and an echocardiogram consistent with an AMI should probably undergo coronary angiography. However, this strategy is unproven and will require further study. 
Competing interests: None declared.

\section{References}

1. Anto MJ, Cokinos SG, Jonas E. Acute anterior wall myocardial infarction secondary to blunt chest trauma. Angiology 1984; 35(12):802-4.

2. Atalar E, Acil T, Aytemir K, Ozer N, Ovunc K, Aksoyek S, et al. Acute anterior myocardial infarction following a mild nonpenetrating chest trauma. Angiology 2001;52(4):279-82.

3. Banzo I, Montero A, Uriarte I, Vallina N, Hernandez A, Guede $\mathrm{C}$, et al. Coronary artery occlusion and myocardial infarction: a seldom encountered complication of blunt chest trauma. Clin Nucl Med 1999;24(2):94-6.

4. Bennett MR, West JNW, Pentecost BL. Fatal myocardial infarction in hypertrophic cardiomyopathy associated with non-penetrating chest trauma. Int J Cardiol 1991;33(2):317-9.

5. Bjorn-Hansen LS, Thomassen AR, Nielsen TT. Aneurysm of the left anterior descending coronary artery after chest trauma. Eur Heart J 1989;10(2):177-9.

6. Blessing E, Wolpers HG, Hausmann D, Mugge A, Amende I. Posttraumatic myocardial infarction with severe coronary intimal dissection documented by intravascular ultrasound. J Am Soc Echocardiogr 1996;9(6):906-8.

7. Boland J, Limet R, Trotteur G, Legrand V, Kulbertus H. Left main coronary dissection after mild chest trauma. Favorable evolution with fibrinolytic and surgical therapies. Chest 1988; 93(1):213-4.

8. Candell J, Valle V, Paya J, Cortadellas J, Esplugas E, Ruis J. Post-traumatic coronary occlusion and early left ventricular aneurysm. Am Heart J 1979;97(4):509-12.

9. Cherng W, Bullard MJ, Chang H, Lin F. Diagnosis of coronary artery dissection following blunt chest trauma by transesophageal echocardiography. J Trauma 1995;39(4):772-4.

10. Chun JH, Lee SC, Gwon HC, Lee SH, Hong KP, Seo JD, et al. Left main coronary artery dissection after blunt chest trauma presented as acute anterior myocardial infarction: assessment by intravascular ultrasound. J Korean Med Sci 1998;13(3):325-7.

11. Espinosa R, Baduli E, Castano R, Madrid R. Acute posteroinferior wall myocardial infarction secondary to football chest trauma. Chest 1985;88(6):928-30.

12. Esplugas E, Barthe JE, Sabate J, Fontanillas C. Obstruction of aortocoronary bypass due to blunt chest trauma. Internat J Cardiol 1983;3(3):311-4.

13. Fang BR, Li CT. Acute myocardial infarction following blunt chest trauma. Eur Heart J 1994;15(5):705-7.

14. Fu M, Wu CJ, Hsieh MJ. Coronary dissection and myocardial infarction following blunt chest trauma. J Formos Med Assoc 1999;98(2):136-40.

15. Gallego FG, Marti JS, Blasco PP. Myocardial infarction and subtotal obstruction of the anterior descending coronary artery caused by trauma in a football player. Int J Cardiol 1986; 12(1):109-12.

16. Gaspard P, Clermont A, Villard J, Amiel M. Non-iatrogenic trauma of the coronary arteries and myocardium: contribution of angiography - report of six cases and literature review. Cardiovasc Intervent Radiol 1983;6(1):20-9.

17. Gillebert Th, Van De Werf F, Piessens J, De Geest H. Post-traumatic infarction due to blunt chest trauma. Acta Cardiologica 1980;35(6):445-53.

18. Ginzburg E, Dygert J, Parra-Davila E, Lynn M, Almeida J, Mayor M. Coronary artery stenting for occlusive dissection after blunt chest trauma. J Trauma 1998;45(1):157-61.

19. Goktekin O, Unalir A, Gorenek B. Traumatic total occlusion of left main coronary artery caused by blunt chest trauma. J Invasive Cardiol 2002;14(8):463-5.

20. Grady AE, Cowley MJ, Vetrovec GW. Traumatic dissecting coronary arterial aneurysm with subsequent complete healing. Am J Cardiol 1985;55(11):1424-5.

21. Greenberg J, Salinger M, Weschler F, Edelman B, Williams R. Circumflex coronary artery dissection following waterskiing. Chest 1997;113(4):1138-40.

22. Gustavsson CG, Albrechtsson U, Forsling K, Stahl E, White T. A case of right coronary artery occlusion, caused by blunt chest trauma and treated with acute coronary artery bypass surgery. Eur Heart J 1992;13(1):133-6.

23. Jensen S, Kristensen IB, Kristensen BO. Lethal myocardial infarction subsequent to compression of the left anterior descending coronary artery induced by traumatic hematoma. Int J Legal Med 1992;105(2):121-2.

24. Kahn JK, Buda AJ. Long-term follow-up of coronary artery occlusion secondary to blunt chest trauma. Am Heart J 1987; 113(1):207-10.

25. Kohli S, Saperia GM, Waksmonski CA, Pezzella S, Singh JB. Coronary artery dissection secondary to blunt chest trauma. Cathet Cardiovas Diag 1988;15(3):179-83.

26. Lascault G, Komajda M, Drobinski G, Grosgogeat Y. Left coronary artery aneurysm and anteroseptal acute myocardial infarction following blunt chest trauma. Eur Heart J 1986;7(6):538-40.

27. Lau OJ, Shabbo FP, Smyllie J. Acute left anterior descending coronary artery occlusion following blunt chest injury. Injury 1984;16(1):55-6.

28. Lee HY, Ju YM, Lee MH. A case of post-traumatic coronary occlusion. Korean J Intern Med 1991;6(1):33-7.

29. Lijoi A, Tallone M, Parodi E, Dottori V, Passerone GC, Rovere FD, et al. Coronary occlusion secondary to blunt chest trauma: a first attempt at balloon angioplasty. Texas Heart Inst J 1992;19(4):291-3.

30. MacDonald D. Repeated and fatal coronary thrombosis in a young man. JAMA 1941;115(26):2846-8. 
31. Mairesse GH, Timmermans P. Post traumatic myocardial infarction. Acta Clin Belg 1993;48(2):128-31.

32. Malangoni MA, McHenry CR, Jacobs DG. Outcome of serious blunt cardiac injury. Surger. 1994;116(4):628-33.

33. Marik PE. Coronary artery dissection after a rugby injury. A case report. S Afr Med J 1990;77(11):586-7.

34. Masuda T, Akiyama H, Kurosawa T, Ohwada T. Long-term follow-up of coronary artery dissection due to blunt chest trauma with spontaneous healing in a young woman. Inten Care Med 1996;22(5):450-2.

35. Meluzin J, Groch L, Toman J, Hornacek I, Fischerova B. Rupture of the coronary artery after blunt nonpenetrating chest wall trauma detected by color Doppler echocardiography: a case report. J Am Soc Echocardiogr 2000;13(11):1043-6.

36. Moore JE. Acute apical myocardial infarction after blunt chest trauma incurred during a basketball game. J Am Board Fam Pract 2001;14(3):219-22.

37. Neiman J, Hui WK. Posteromedial papillary muscle rupture as a result of right coronary artery occlusion after blunt chest injury. Am Heart J 1992;123(6):1694-9.

38. Oliva PB, Hilgenberg A, McElroy D. Obstruction of the proximal right coronary artery with acute inferior infarction due to blunt chest trauma. Ann Int Med 1979;91(2):205-7.

39. O’Neill S, Walker F, O'Dwyer WF. Blunt chest trauma causing myocardial infarction - an unusual football injury. Irish Med J 1981;74(5):138.

40. Orbe LC, Gallego FG, Sobrino N, Sotillo J, Lopez-Sendon JL, Oliver J, et al. Acute myocardial infarction after blunt chest trauma in young people: need for prompt intervention. Catheter Cardiovasc Diagn 1991;24(3):182-5.

41. Oren A, Bar-Shlomo B, Stern S. Acute coronary occlusion following blunt injury to the chest in the absence of coronary atherosclerosis. Am Heart J 1976;92(4):501-5.

42. Pande AK, Hajar HA. Chest trauma causing acute myocardial infarction. J Assoc Physicians India 2001;49:1111-3.

43. Park WS, Jeong MH, Hong YJ, Park OY, Kim JH, Kim W, et al. A case of acute myocardial infarction after blunt chest trauma in a young man. J Korean Med Sci 2003;18(6):889-93.

44. Pretre R, Kursteiner K, Khatchatourian G, Faidutti B. Traumatic occlusion of the left anterior descending artery and rupture of the aortic isthmus. J Trauma 1995;39(1):388-90.

45. Pringle SD, Davidson KG. Myocardial infarction caused by coronary artery damage from blunt chest injury. Br Heart J 1987;57(4):375-6.

46. Salmi A, Blank M, Slomski C. Left anterior descending artery occlusion after blunt chest trauma. J Trauma 1996;40(5):832-4.
47. Shapiro MJ, Wittgen C, Flynn MS, Zuckerman DA, Durham RM, Mazuski JE. Right coronary artery occlusion secondary to blunt trauma. Clin Cardiol 1994;17(3):157-9.

48. Sigmund M, Nase-Huppmeier S, Uebis R, Hanrath P. Emergency PTCA for coronary artery occlusion after blunt chest trauma. Am Heart J 1990;119(6):1408-10.

49. Sinha AK, Agrawal RK, Singh A, Kumar R, Kumar S, Sinha A, et al. Acute myocardial infarction due to blunt chest trauma. Indian Heart J 2002;54(6):713-4.

50. Stern T, Wolf RY, Reichart B, Harrington OB, Crosby G. Coronary artery occlusion resulting from blunt trauma. JAMA 1974;230(9):1308-9.

51. Stone DL, Fleming HA. Aneurysm of left ventricle and left coronary artery after non-penetrating chest trauma. Br Heart $\mathbf{J}$ 1983;50(5):495-7.

52. Unterberg C, Buchwald A, Wiegand V. Traumatic thrombosis of the left main coronary artery and myocardial infarction caused by blunt chest trauma. Clin Cardiol 1989;12(11):672-4.

53. Vlay SC, Blumenthal DS, Shoback D, Fehir K, Bulkley BH. Delayed acute myocardial infarction after blunt chest trauma in a young woman. Am Heart J 1980;100(6):907-16.

54. Voyce SJ, Ball SP, Gore JM, Shine WJ, Weiner BH. Angiographically documented thrombotic coronary artery occlusion secondary to mild nonpenetrating thoracic trauma. Catheter Cardiovasc Diagn 1991;24(3):179-81.

55. Wainwright RJ, Edwards AC, Miasley MN, Sowton E. Early occlusion and late stricture of normal coronary arteries following blunt chest trauma. Chest 1980;78(5):796-8.

56. Wang S, Shyong W, Tsai J, Chang M, Chiang B. Development of posttraumatic coronary aneurysm: clinical implications. Am Heart J 1988;115(6):1306-7.

57. Watt AH, Stephens MR. Myocardial infarction after blunt chest trauma incurred during rugby football that later required cardiac transplantation. Br Heart J 1986;55(4):408-10.

58. Westaby S, Drossos G, Giannopoulos N. Posttraumatic coronary artery aneurysm. Ann Thoracic Surg 1995;60(3):712-3.

59. Berk WA. ECG findings in non-penetrating chest trauma: a review. Emerg Med 1987;5(3):209-15.

60. Tsoukas A, Andreades A, Zacharogiannis C. Myocardial contusion presented as acute myocardial infarction after chest trauma. Echocardiography 2001;18(2):167-70.

Correspondence to: Dr. Gregory Guldner, Loma Linda University Medical Center, Department of Emergency Medicine, 11234 Anderson St., Rm. A108, PO Box 2000, Loma Linda CA 92354; gregguldner@jfmilne.com 